retired and taken another occupation. ${ }^{\prime}$ This is illustrated by the finding that 22 out of a sample of 2196 deaths were assigned to the armed forces on death certification, while only 11 were similarly assigned at the corresponding census. ${ }^{2}$ As a result, the SMRs for the armed forces are always spuriously high, and in such circumstances it cannot be assumed that the SMRs for all diseases are equally affected. Indeed, it is most unlikely that they are.

Dr Sorahan has sought to overcome this difficulty by citing relative SMRs-that is, by expressing each disease specific SMR as a proportion of the SMR for all causes. This avoids the general bias of overrepresentation of service occupations on death certificates, though not of any differential bias affecting different diseases, but it does so at the cost of expressing the results in the form of proportions. Proportions, however, depend on both the risk of death from the causes of interest and the multitude of other risks that are responsible for other causes, and their interpretation is extremely difficult.

We therefore preferred to omit reference to the Registrar General's occupational mortality data in our report. If, however, they are to be used, the most relevant are those reported in the 198 decennial supplement, ${ }^{1}$ as about $60 \%$ of the death in our series occurred between 1975 and 1983 .

Other evidence bearing on the interpretation of our results that has become available since our report is provided by a national study of 399 cases of multiple myeloma and 399 controls carried out by the Imperial Cancer Research Fund (J Cuzick, personal communication). This shows that roughly equal proportions of cases and controls had served in the armed forces in tropical or subtropical areas and implies that such service was not associated with any unusual incidence of the disease. It supports our contention that the difference in mortality from multiple myeloma that we observed between participants (SMR 111) and controls (SMR 0), which was a major component of the difference in mortality from neoplasms of the reticuloendothelial system, was principally due to an atypically low mortality in the controls.

\section{SC DARBY}

R DolL

ICRF Cancer Epidemiology and Clinical Trials Unit, Radcliffe Infirmary, Oxford OX2 6HE

\section{R MUIRHEAD}

\section{National Radiological Protection Board,}

Chilton, Didcot, Oxfordshire

1 Office of Population Censuses and Surveys. Occupational mortality 1979-80, 1982-83 decennial supplement for Great Britain. 1979-80, 1982-83 decennial supplement
London: HMSO, 1986. (Series DS No 6.)

2 Registrar General. Occupational mortality 1961 decennial supplement for England and Wales. London: HMSO, 1971.

\section{Clumsy children}

SIR,-Clumsiness is a reflection of motor learning difficulty and commonly self limiting in children, but the interaction between motor competence and temperament should be emphasised.

The way in which clumsiness and anxiety by age 7 have predictive value for psychiatric outcome at 17 years was recently described by Shaffer $e t a l$, who found little evidence to suggest that clumsiness is usually caused by anxiety. Eighty per cent of anxious, clumsy 7 year old children turned out well. However, the great majority of adolescents with anxiety states, depression, or withdrawal (but not conduct disorder or substance abuse) came from the remaining $20 \%$. Neither clumsiness nor anxiety alone predicted psychiatric breakdown in later years. This has implications for neurodevelopmental screening, mental health prophylaxis, and intervention.
Neurodevelopmental screening for clumsiness at school entry was shown to predict motor competence at $81 / 2$ years in a controlled study of over 11000 Cheshire children at a $1 \cdot 2 \%$ cut off level. ${ }^{2}$ However, a $10 \%$ cut off level for clumsiness was not found to be predictive after two years in north Manchester, ${ }^{3}$ presumably reflecting the influence of normal variation. There is little point in identifying clumsiness in aspects of motor ability in children who are causing no concern.

However, clumsiness is an issue for many children with health problems, including hydrocephalus, epilepsy, leukaemia treated by cranial irradiation in early years, congenital hypothyroidism treated after the neonatal period, intrauterine growth retardation, mild mental retardation including fragile $\mathrm{X}$ anomaly, ${ }^{45}$ albinism, and language disorders. ${ }^{67}$

There are concerns about the reliability and validity of present coordination tests, ${ }^{8}$ and there is a lack of evidence about the effectiveness of physical intervention. None the less, appreciation that the combination of anxiety and clumsiness is likely to be present in those who come to attention will be helpful. Growing ingenuity in methods of helping children with handwriting difficulties ${ }^{10}$ and the formation of a self help organisation for families (the Dyspraxia Trust, 12 The Larches, Ware SG12 0XJ) are helpful developments.

There is much to be learnt about the causes of persistent clumsiness in those who have no associated medical problems, but genetic influences may have been underestimated in terms of natural endowment and reduced capacity to withstand insults such as perinatal asphyxia."

Community Services,

Salford Health Authority

Manchester M20 0N

IAN MCKINLAY

1 Shaffer D, Schonfield I, O'Connor PA, et al. Neurological soft signs: their relationship to psychiatric disorders and intelligence in childhood and adolescence. Arch Gen Psychiatry 1985;42:342-51.

2 McKinlay I, England A, Nash S, et al. The predictive value of coordination testing. Neuropediatrics 1981;12(suppl):426.

3 Ehrhardt P, McKinlay IA, Bradley G. Co-ordination screening for children with and without moderate learning difficulties: further experience of Gubbay's tests. Dev Med Child Neurol 1987;29:666-73.

4 McKinlay I. Why are they clumsy? In: Gordon N, McKinlay I, eds. Helping clumsy children. Edinburgh: Churchill Livingstone, 1980 .

5 McKinlay I, Bradley G, Hindle A, et al. Motor co-ordination of children with mild mental handicap. Ups $\mathcal{F}$ Med Sci [Suppl] children with mild

6 Cole GF, Conn P, Jones RB, et al. Cognitive function in albino children. Dev Med Child Neurol 1987;29:659-65.

7 Bishop DVM, Edmundson A. Specific language impairment as a maturational lag: evidence from longitudinal data on language and motor development. Dev Med Child Neurol 1987;29:442-59.

8 Shafer SQ, Shaffer D, O'Connor PA, et al. Hard thoughts on neurological "soft signs." In: Rutter M, ed. Development neuropsychiatry. Edinburgh: Churchill Livingstone, 1984.

Alston J, Taylor J. Handwriting: theory, research and practice. London: Croom Helm, 1987.

10 McKinlay I. Children with motor learning difficulties: not so much a syndrome-more a way of life. Physiotherapy 1987; 73:635-8.

11 Brown JK. Infants damaged during birth: perinatal asphyxia. In: Hull D, ed. Recent advances in paediatrics 5 . Edinburgh: Churchill Livingstone, 1976

SIR,-While agreeing with the good sense of most of what Dr D M B Hall said in his leading article (6 February, p 375), I must disagree with his last sentence.

It may well be that clumsy children form the lower end of a normal distribution of motor skills and can therefore be described as merely lacking in talent, but the same cannot be said for "other learning disabilities." It is certainly true that they present severe educational problems, but paediatricians cannot just wash their hands of them.
Reading more than 2 SDs below that predicted from performance IQ would be expected in $2 \cdot 5 \%$ of "normal" children. Instead it is eight times commoner than this in boys and twice as common in girls, so that approximately $10 \%$ of $8-12$ year olds are found to have such specific reading retardation. On account of the unusual sex ratio, strong familial tendency, correlation with perinatal problems, and similarities with acquired reading difficulties resulting from cortical lesions many neurologists term the condition "developmental dyslexia" in recognition of its probable organic origin. Labelling it merely an educational problem is not only probably wrong but it discourages the search for physiological mechanisms; and, worse, it misleads teachers, parents, and the children themselves into believing that it is they who are responsible for the failures of dyslexics.

J F STEIN

University Laboratory of Physiology,

Oxford OX1 3PT

\section{Achieving a Balance-a time for action}

SIR,-Achieving a Balance-a plan for action aims to reduce the number of British graduates seeking a career in medicine and surgery, so that numbers of registrars correspond more closely to numbers of senior registrars, which should themselves equate with likely consultant vacancies.

The current problem is that too many registrars wish to pursue higher training, and nowhere is this more evident than in general surgery. The specialist advisory committee in surgery has identified about 500 postfellowship trainees who intend to pursue a career in general surgery. The proposed number of career registrars under Achieving a Balance would be about 180 .

The bottleneck at the senior registrar grade is showing itself in the quantity and quality of applicants for senior registrar appointments. I have performed an analysis of the applications that were made to a recent advertisement for a senior registrar in general surgery in South Glamorgan and Gwent.

There were 51 applicants, 49 men and two women, aged 32 to 37 , with a mean age of 34 (SD 1.6) years. Three came from India, two from Ireland, and one each from Australia, Sri Lanka, and Pakistan. Forty three were married and 30 had children.

The applicants received their training in many different medical schools. Eighteen had qualified in London and six in Cardiff. They had held the FRCS for a mean of $5.2(1 \cdot 4)$ years and had spent a mean of $6.0(1.5)$ years in the registrar grade. Thirty nine had spent one (11), two (22), or three (6) years in research posts, 31 in Britain, eight overseas; $80 \%$ had undertaken a thesis, which was being written up by 15 , submitted by nine, and accepted in 17 cases. All but four had publications with a mean of $7 \cdot 9(6 \cdot 5)$ (range $0-24)$. The number of publications of which the candidate was the first author was 4.5 (3.8) papers (range 0-14); the mean number of abstracts published was $6 \cdot 1(6.9)$ (range $0-35)$, and the number of presentations was $11 \cdot 7$ $(10 \cdot 4)(0-54)$.

The applications came from all parts of the country, although 16 came from the London area. There were three local candidates. Thirty one were currently registrars, four research registrars, four locum registrars, seven locum senior registrars, two locum consultants, and one a consultant abroad. Two candidates were unemployed.

Most of the applicants deserved higher surgical training in Britain. At their age and level of training it would be very difficult for most of them to retrain in another specialty. These young men and women have served the health service well, 
and we owe it to them to ensure that they ultimately progress to a senior registrar appointment.

For this reason I would urge that Achieving a Balance is instituted as soon as possible and that target numbers for career registrars should be achieved within the shortest time possible. This will seriously curtail and may even prevent the entry of new trainees over the next few years, but this has to happen if the majority of those currently in training are to be given a chance of progressing to the senior registrar grade.

Department of Surgery,

J R SALAMAN

University of Wales College of Medicine,

Cardiff CF2 1SZ

\section{Pitfalls in the glucose tolerance test}

SIR,-I am grateful to Dr Hilary King and colleagues (30 January, p 357), representing the World Health Organisation and the United States National Institutes of Health, for their authoritative comments on issues raised in my leading article (28 November, p 1363).

On the topic of whether $75 \mathrm{~g}$ of anhydrous or monohydrous glucose should be used for the glucose tolerance test they say that most data have been obtained using $75 \mathrm{~g}$ of "pure" glucose and that this should be adhered to. In the survey I carried out over half of the 230 participating laboratories claimed to be administering the dose as the monohydrate. Most of the commercial preparations for glucose tolerance tests are packaged to give a dose of $75 \mathrm{~g}$ of the monohydrate, whether in the form of glucose powder or ready made solution. In the case of the glucose syrup preparation Lucozade the manufacturer recommends a volume of 235 or $353 \mathrm{ml}$ as equivalent to 50 or $75 \mathrm{~g}$ respectively of glucose monohydrate.

There is, however, confusion in the published reports. Some workers have said that $235 \mathrm{ml}$ of Lucozade is equivalent to $50 \mathrm{~g}$ of anhydrous glucose, ${ }^{12}$ while others have been less specific, saying it is equivalent to $50 \mathrm{~g}$ of "liquid glucose." 34

The term "pure glucose" used by Dr King and others is also ambiguous. To them it obviously means anhydrous glucose, but to others it can mean either form, as distinct from glucose syrup preparations, which also contain higher molecular weight carbohydrates that are digested to glucose. Furthermore, I think the World Health Organisation's first report on this topic in 1965 actually recommended using a dose of glucose monohydrate (then $50 \mathrm{~g}$ ).

Clearly, the situation is confusing and while I have no very strong views on whether we should be using $75 \mathrm{~g}$ of anhydrous or monohydrous glucose, I do put in a plea for uniformity throughout the world and would ask the World Health Organisation to state its preference clearly and to publicise it as widely as possible so that all interested partiesclinical laboratories, clinicians, pharmacy departments, and specialist manufacturers-will be aware of it: they certainly are not at present.

Department of Clinical Biochemistry

K WIENER

North Manchester General Hospital,

Manchester M8 6RB

1 Boyns DR, Crossley JM, Abrams ME, et al. Oral glucose tolerance and related factors in a normal population sample. tolerance and related fact

2 Reid DD, Brett GZ, Hamilton PJS, et al. Cardiorespiratory disease and diabetes among middle-aged male civil servants: a study of screening and intervention. Lancet 1974;i;469-73.

3 Jarrett RJ, Keen H. Diurnal variation of oral glucose tolerance: a possible pointer to the evolution of diabetes mellitus. BrMed $\mathcal{f}$ 1969;ii:341-4.

4 Jarrett RJ, Baker JA, Keen H, Oakley NW. Diurnal variation in oral glucose tolerances: blood sugar and plasma insulin levels morning, afternoon and evening. Br Med f 1972;i: 199-201.
SIR,-The World Health Organisation recommends using a $75 \mathrm{~g}$ load for the oral glucose tolerance test. This is a compromise between the $50 \mathrm{~g}$ load widely used in Europe, which has been criticised for insufficient provocation, and the 100 $\mathrm{g}$ load used in the United States, which often causes nausea. Despite these recommendations there is still much variation in the type and quantity of glucose given as part of the test. This has been pointed out by $\mathrm{Dr} \mathrm{K}$ Wiener (28 November, p 1363) and Dr H King and others (30 January p 357).

The results of an oral glucose tolerance test are often used to define normality, impaired glucose tolerance, and diabetes mellitus. Small differences in blood glucose concentrations can have profound implications for patients. Although small variations in the quantity of glucose given do no produce significant variations in blood glucose levels, it is important to define precisely the protocol for the test.

Dr Weiner explains the problems in interpreting the term "75 g of glucose." We suspect that mos laboratories would supply $75 \mathrm{~g}$ of glucose as the anhydrous compound or an equivalent quantity of the monohydrate. Pharmacy departments would refer to the British Pharmacopoeia and find that glucose $B P$ was in fact glucose monohydrate. They would supply $75 \mathrm{~g}$ of glucose monohydrate (equivalent to $67 \cdot 5 \mathrm{~g}$ of glucose anhydrate). If the Système International d'Unités were used for both prescription and supply these misunderstandings would be avoided. We agree with $\mathrm{Dr}$ King that the glucose used in the oral glucose tolerance test should be defined as $75 \mathrm{~g}$ of glucose anhydrate $\mathrm{C}_{6} \mathrm{H}_{12} \mathrm{O}_{6}$ (or $82.5 \mathrm{~g}$ of glucose monohydrate $\mathrm{C}_{6} \mathrm{H}_{12} \mathrm{O}_{6} \cdot \mathrm{H}_{2} \mathrm{O}$ ). Future publications from national and international organisations must be precise about the degree of hydration of the glucose to be used.

S J EvaNS

Departments of Clinical Chemistry and Pharmacy,

General Hospital,

Northampton NN3 5BD

\section{Paediatric oncology information pack}

SIR,-Dr J A James and his colleagues (9 January, p 97) report on a valuable initiative to improve communication between a paediatric oncology unit and general practitioners by providing an information pack for general practitioners on the management of childhood cancer. In the same issue Dr Nick Black ( $p$ 82) comments on the potential gains to be had from partnership between health authorities and voluntary organisations. Information sharing is a good example of these benefits Information provided by the voluntary agencies often distils the experiences of families and other carers in a form that can benefit those with responsibility for medical management of the child. Effective communication over the care of sick children and the support of their parents should also include other primary care workers and representatives of family carers.

Voluntary organisations have often taken the lead in providing information to health professionals about the needs of families with particular problems and to parents about rare conditions and available support. Information which user groups have helped to prepare can be particularly useful in drawing attention to the non-medical needs of parents, but volunteers and other carers also have considerable practical experience of the organisational barriers to providing sensitive health care to children. Their experience indicates that improved communication between agencies and more widely available information about the management of serious conditions could reduce the difficulties experienced by parents before and immediately after diagnosis, while caring for a sick or handicapped child, and when facing bereavement. ${ }^{1-3}$

Coordination would also be improved by the wider distribution of background information on the management of rare conditions. Those who could usefully benefit from the information include clinical medical officers, community nurses, social workers, head teachers, and voluntary groups. Most primary care teams do not yet have sufficiently established routine contacts with these other agencies to enable them to take responsibility for passing on general information. In particular, as the Bristol study showed, distributing information to general practitioners alone is likely to result in patchy dissemination to community nursing staff. Consultant community paediatricians might be best placed to provide overall coordination and to circulate relevant information.

Gaps in community provision-such as nursing support for sick children-might be more clearly identified if there were clearer channels of communication between hospital and primary care workers. The benefits of such consultation will, however, be attained only when communication is two way. Staff in specialist units could benefit from knowing what community resources are available, and the unit could be a useful route for introducing parents to local contacts. Parents who have experienced similar problems also have a great deal to offer and their views can be invaluable in ensuring that arrangements are sensitive to parents' needs.

Lisa Curtice

Maternity Alliance,

London WCIX 9JP, and

Department of Community Health,

University of Liverpool

1 Kohner N, ed. After stillbirth and neonatal death: what happens next? London: Stillbirth and Neonatal Death Society, 1986: 22.

2 Ashelford T. Minding children with special needs, Bromley: National Childminding Association, 1987.

3 Neale T. Cystic fibrosis project: a survey of the needs of families in the Midlands area. Halesowen: Barnardo's Midlands Division, 1987.

\section{Shift system for a neonatal intensive care unit}

SIR,-Having worked as a neonatal senior house officer for Dr Brian Speidel at Southmead Hospital I was interested to see his recent description of the "shift" rota (30 January, p 343). The objectives of introducing this rota were twofold: to improve care of the babies and to make life more tolerable for the senior house officers in a specialty with a heavy night time workload.

The system has a number of advantages for the operation of the unit. In particular, working continuously in special care baby units for a week allows the senior house officer to develop a more thorough knowledge of the problems and progress of each baby than is gained when covering only every fourth day, as previously occurred. This improves the continuity and, it is hoped, the standard of care.

There are still disadvantages, however, for the senior house officers concerned. The main problem is that although nominally on a 1 in 4 rota they effectively work 1 in 2 . Long shifts fully occupy alternate weekends and although the paper points out that social activities must be curtailed during the week of night shifts, they are also severely restricted during the week of long days since the nominal finishing time of 2100 or 2300 is often overrun when problems occur in the special care baby unit or the delivery suite.

Dr Speidel correctly points out that the longest 